\title{
Direitos trabalhistas e organização dos trabalhadores num contexto de mudanças no mundo do trabalho: efeitos sobre os trabalhadores da saúde
}

Elina Gonçalves da Fonte Pessanha ${ }^{1}$

Karen Artur ${ }^{1}$

\author{
Labor rights and the organization of workers \\ in a context of change in labor relations: effects on health workers
}

\begin{abstract}
This paper presents the main institutional changes in labor relations in Brazil, highlighting their impact on the organization of workers. A more recent central change is the regulation of outsourcing by the Labor Judiciary. Research into claims in the Superior Labor Court, guidelines from the Labor Prosecution Office, and trade union lawsuits, show that outsourcing and working hours are subjects which have directly affected health workers. By addressing the institutional principles of justice in contracts, it was concluded that labor reform should deal with the inequality of rights that have characterized the Brazilian labor market.
\end{abstract}

Key words Sociology of labor, Labor rights, Outsourcing, Health workers

\footnotetext{
${ }^{1}$ Programa de PósGraduação em Sociologia e Antropologia, Instituto de Filosofia e Ciências Sociais, Universidade Federal do Rio de Janeiro. Largo São Francisco 1/418, Centro. 20051-070 Rio de Janeiro RJ. elina.pessanha@terra.com.br
}

Resumo Este artigo apresenta as principais mudanças institucionais do mundo do trabalho no Brasil, apontando seus impactos para a organização dos trabalhadores. Uma mudança central, mais recente, é a regulação da terceirização pelo Judiciário Trabalhista. Pesquisas de demandas no Tribunal Superior do Trabalho, de orientações do Ministério Público do Trabalho e de ações sindicais mostram que terceirização e jornada de trabalho são temas que têm afetado diretamente os trabalhadores da saúde. Por meio de uma abordagem sobre as bases institucionais da justiça nos contratos, concluímos que a reforma trabalhista deve tratar da desigualdade de direitos que tem marcado o mercado de trabalho brasileiro.

Palavras-chave Sociologia do trabalho, Direitos do trabalho, Terceirização, Trabalhadores da saúde 


\section{Introdução}

Direitos trabalhistas e organização dos trabalhadores são temas intimamente relacionados. Nunca é demais lembrar que o Direito do Trabalho e mais especificamente o primeiro corpo de legislação trabalhista, surgido durante a República de Weimar na segunda década do século XX, e em parte encampado pela nascente OIT, apresentam a possibilidade de demandas coletivas e não individuais apenas, como previa a chamada justiça comum, civil - serem encaminhadas aos patrões e, eventualmente, a juízes e tribunais.

Os sindicatos, uma criação do século XIX inicialmente na Inglaterra, exemplo de abstenção legal e não intervenção do Estado nos conflitos entre capital e trabalho - foram desde então os portadores dessa vontade coletiva, organizadores das lutas e guardiões da efetivação das conquistas da classe trabalhadora.

Se os direitos individuais também foram e são objeto de reclamações diretas ou via justiça, dos trabalhadores, a configuração e a legitimidade dos direitos coletivos constitui sem dúvida um diferencial do Direito do Trabalho, que só mais recentemente encontrou um paralelo no reconhecimento, no plano da justiça civil, dos direitos metaindividuais, difusos e coletivos.

$O$ formato que a relação entre sindicatos de trabalhadores e a defesa de direitos trabalhistas toma nas circunstâncias particulares das diferentes nações capitalistas, tem variações obviamente. A ausência ou a presença da mediação do Estado, e a natureza dessa intervenção, tem sido certamente um dos fatores mais importantes dessa diferenciação. No caso do Brasil, onde durante a experiência, digamos, mais "liberal" da primeira república, os trabalhadores e reformadores sociais conquistaram algumas poucas leis protetivas do trabalho, a Revolução de 30 marca a entrada em cena do Estado como mediador privilegiado dos conflitos trabalhistas. Calçado no que temos chamado de um "consenso antiliberal”, reunindo Igreja Católica, setores da esquerda e corporativistas, Vargas impôs o projeto de uma justiça especial, do trabalho (1941), e logo de uma consolidação de leis (a CLT de 1943), à revelia da reação "liberal" que se fez sentir desde os primeiros momentos.

O embate entre liberais (hoje neo) e seus críticos dá, na verdade, o tom de fundo do nosso debate trabalhista, acirrando posições. Isso muitas vezes tem impedido que vícios reconhecidos do modelo elaborado na Era Vargas sejam enfrentados, e que no ambiente mais democrático em que vivemos atualmente no Brasil, trabalhemos para aprimorar esse modelo protetivo, resistente ao tempo e às adversidades e enraizado como uma cultura de nossos direitos sociais mais profundos.

Mas como chegamos ao período da reestruturação produtiva, basicamente os anos 1990, no caso brasileiro, em termos de direitos trabalhistas e organização dos trabalhadores? E em que isso afeta os trabalhadores da saúde?

\section{Construindo os direitos trabalhistas, sob autoritarismo e na democracia}

A Revolução de 30 acelerou o processo de regulação e de montagem de uma nova estrutura para gerir as relações trabalhistas. Com a criação do Ministério do Trabalho, seu primeiro Consultor Jurídico, Evaristo de Moraes redigiu com Joaquim Pimenta, em 1931, o Decreto $19770^{1}$, que tinha por objetivo regular "a sindicalização das classes patronais e operárias”. Instala-se o novo Departamento Nacional do Trabalho junto ao qual, em 1932, passam a funcionar as Comissões Mistas de Conciliação (com 6 representantes de trabalhadores e 6 de patrões, para tentar conciliar impasses coletivos) e as Juntas de Conciliação e Julgamento ( 1 representante de trabalhadores, 1 de patrões, 1 bacharel, para julgar as questões trabalhistas individuais). A Constituição de 1934 instituiu na letra a Justiça do Trabalho "para dirimir questões entre empregadores e empregados, regidas pela legislação social”, mas a implantação do projeto despertou a reação dos liberais, que não queriam uma justiça federal tão distante e acima dos interesses locais bem sedimentados. Não queriam também que os sindicatos funcionassem como pessoas jurídicas públicas, alegando que a vontade individual dos trabalhadores deveria prevalecer. Não aceitavam, na verdade, a existência de sujeitos e direitos coletivos e não queriam uma Justiça do Trabalho com o que consideravam o poder de legislar: eram frontalmente contra o poder normativo. Somente após 1937, já no Estado Novo de Vargas, o projeto foi imposto e incorporou mecanismos de enrijecimento da estrutura sindical e de seu controle. É essa Justiça, ainda com sua natureza jurídica pouco definida, que irá controlar, a partir de 1943, o cumprimento da Consolidação das Leis do Trabalho, a CLT, seguindo Moraes Filho ${ }^{2}$

A CLT original regulava os direitos e definia o perfil desejado dos sindicatos e os limites de sua atuação. Enquadrava os grupos profissio- 
nais por setores, controlava a formação das associações, seu funcionamento e sua reprodução. Exigia a unicidade sindical e previa o imposto compulsório que financiava o sistema. E inibia a greve. Esse quadro não mudou muito no período de redemocratização de 1945 a 1964, como sabemos, embora tenha havido maior tolerância com as manifestações dos trabalhadores no fim do período e conquistas importantes tenham sido alcançadas por setores mais agressivos da classe.

A ampla e difusa base social de apoio, aliada à funcionalidade dos instrumentos de controle e aos direitos que nossa legislação trabalhista consolidou, explica em grande parte a continuidade e a resistência desse modelo de relações de trabalho. Tem início aí um gradual processo de enraizamento de uma cultura de direitos que, mesmo atingindo apenas um grupo privilegiado de trabalhadores (urbanos, do setor privado, com vínculo empregatício), se tornaria uma referência fundamental, em termos sociais, para a totalidade dos trabalhadores de nosso país. Ajustandose tanto às mudanças de regime político quanto àquelas provocadas pelo processo de modernização que se acelera em determinados momentos como entre 1950 e 1963, os traços fundamentais do modelo permaneceram. Atravessaram o regime autoritário pós-64, que estrategicamente suspendeu alguns direitos importantes, como o da estabilidade - substituído pelo FGTS -, além de reforçar o uso dos aspectos repressivos já contidos na legislação.

Com o prenúncio da abertura democrática a partir principalmente da década de 1980, esperava-se que os temas centrais às relações de trabalho seriam retomados pelos trabalhadores, mas o declínio do crescimento industrial e econômico dos anos anteriores e o violento processo inflacionário, acabaram levando a uma agenda sindical defensiva, centrada principalmente na recuperação de direitos (de representação dos trabalhadores, de greve), embora sem perder de vista uma possível reforma da legislação trabalhista e a expansão da cidadania social e política. Na verdade, o "novo sindicalismo" dos setores dinâmicos da indústria paulista - logo incorporando outros segmentos, inclusive médios e de servidores públicos - com suas greves, negociação direta com o patronato, maior participação das bases sindicais, prioridade aos problemas nos locais de trabalho, terminou por produzir, nesse contexto, respostas mistas ao sistema. Expressava-se o confronto político, sem colocar inteiramente em cheque os velhos estatutos. Nessa linha, a segunda metade da década de 1980 é um período de explo- são das demandas dos trabalhadores e também de expansão do acesso à justiça.

A Constituição de 1988 representa um momento de ganhos especiais na área trabalhista. Para começar, o seu art. $7^{\circ}$ solidificou o preceito isonômico, atribuindo a igualdade de direitos aos trabalhadores urbanos e rurais, respeitadas as diferenças que exigiam regulamentação distinta. A Carta incorporou boa parte das demandas represadas e anulou alguns dispositivos autoritários da CLT, aumentando a proteção legal do trabalho e defendendo as liberdades sindicais, entre as quais os direitos de greve, de organização e de não intervenção estatal abusiva. Paralelamente, consolidou os poderes atribuídos ao Ministério Público do Trabalho, e também aos sindicatos, de atuarem na defesa de direitos difusos ou coletivos da categoria, através das ações civis públicas. Foram mantidos, entretanto, o monopólio da representação - a unicidade sindical - e o imposto sindical obrigatório.

Legitimado, já em contexto democrático, o modelo de relações trabalhistas nem por isso deixou de se constituir em campo de disputas entre os atores do capital e do trabalho.

\section{A reestruturação produtiva dos anos 1990: desdobramentos para o modelo de relações de trabalho}

A possibilidade de reforma da CLT e da estrutura sindical voltaria fortemente à tona durante o governo Collor (1990/1992), com propostas de clara inspiração (neo) liberal que, no bojo do processo de difusão da reestruturação produtiva, se intensificaram e colocaram em cheque a legislação e os direitos trabalhistas. Durante o governo Itamar Franco, iniciado em outubro de 1992 com o impedimento de Collor, o debate foi retomado e práticas alternativas de negociação - como o "contrato coletivo de trabalho" e as "câmaras setoriais" - foram ainda ensaiadas, com os sindicatos dos setores mais modernos demonstrando sua capacidade de atuação política ${ }^{3-6}$. Em relação ao Plano Real, de estabilização da economia, no entanto, o Tribunal Superior do Trabalho concorreu com várias medidas inibidoras do acesso à justiça por parte dos sindicatos, as quais são apresentadas e analisadas por Pessanha et al. ${ }^{7}$.

De fato, a Constituição de 1988 fortaleceu o poder da Justiça do Trabalho nos momentos de julgamento de dissídios coletivos, confirmando seu poder de criar normas econômicas e sociais, mas essa Justiça logo reagiu ao aumento signifi- 
cativo de greves ocorridas no período com algumas medidas restritivas. Essa retração do judiciário trabalhista ganharia maior fôlego na década de 1990, inclusive com a autolimitação de sua intervenção nos conflitos trabalhistas, não concedendo além daquilo já garantido em lei. Data desse período a Instrução Normativa no 04 do Tribunal Superior do Trabalho (baixada em 1993, revogada em 2003 apenas) que, a título de uniformizar os procedimentos nos dissídios coletivos de natureza econômica, exigiu uma série de formalidades para o ajuizamento da ação, muitas delas quase impossíveis de serem cumpridas. Com isso se precipitou uma situação em que quase todos os dissídios coletivos foram extintos sem julgamento do mérito.

A manifestação mais vigorosa dos interesses do mercado capitalista ocorreu durante o governo de Fernando Henrique Cardoso, quando, sob justificativas que se referiam simplificadamente ao modelo como "da era Vargas", foram tomadas medidas que desrespeitaram os preceitos já então constitucionais, promovendo a precarização e a flexibilização do contrato de trabalho, conforme mostra o trabalho de $\mathrm{Krein}^{8}$. O projeto mais audacioso do governo Cardoso, foi o que instituía a prevalência do negociado (diretamente entre trabalhadores e seus patrões) sobre o legislado. Tal mudança abrupta do modelo de relações trabalhistas não vingou graças à firme reação de associações profissionais do setor jurídico e de sindicatos dos trabalhadores e à sua pressão junto ao Congresso Nacional. O governo ainda operou dentro do discurso da extinção da Justiça do Trabalho, ao mesmo tempo em que teve no TST um interlocutor para propostas de novas formas de solução e de gestão de conflitos trabalhistas, segundo analisa Artur?.

Tentava-se assim, por um lado, diminuir os custos do patronato com a mão-de-obra - garantindo-lhe maiores taxas de lucro e mais liberdade na ocupação oportunista dos trabalhadores. Por outro, o objetivo era atingir a lógica coletiva na defesa dos direitos do trabalho, neutralizá-la e ampliar os espaços de contratações e decisões individualizadas, fora do espaço público e à margem da proteção sindical e da atuação da Justiça do Trabalho (Quadro 1).

É bastante significativo que as pautas das greves tenham mudado significativamente nesse período, como mostra a Tabela 1.

O sentimento de perda de direitos tinha, sem dúvida, fundamento e os procedimentos adotados pelo Tribunal Superior do Trabalho só acentuavam isso, criando dificuldades para que os sindicatos recorressem à justiça. No final da década de 1990, o TST consolidou as atitudes que vinha tomando, buscando causas de nulidades nas práticas sindicais que inviabilizassem sua representação processual. Em 1998 a Seção de Dissídios Coletivos do TST criou ainda seis Orientações Jurisprudenciais para verificar convocações e quóruns de assembleias sindicais em várias circunstâncias. Com isso, o número de dissídios coletivos caiu significativamente, como se vê na Tabela 2.

O governo de Luiz Inácio Lula da Silva logo sepultou a tentativa do governo anterior de fazer valer o "negociado" sobre o "legislado", mas a tensão recorrente entre posturas mais liberais, ou menos, voltou a explicitar-se novamente em torno de duas iniciativas especiais.

A) A da chamada Reforma do Judiciário (Emenda Constitucional 45), projeto que vinha sendo negociado há vários anos, que foi finalmente aprovado no final de 2004, e que reforçou o papel da Justiça do Trabalho pela ampliação de sua competência sobre todas as relações de trabalho - e não só as de emprego formal. Por outro lado, tentou-se inibir o alcance do poder normativo, instrumento central de sua intervenção social e pedra angular da ação reguladora do Estado sobre as relações de trabalho. Alçada à condição alternativa de arbitragem pública quando as partes solicitarem, a Justiça do Trabalho só pode intervir quando se esgotarem as etapas previstas para a composição dos conflitos nos casos de natureza econômica. Esclarecemos que os dissídios econômicos (definidos também como "de interesse" ou "salariais") opõem-se aos de natureza jurídica (ditos "derivados" ou "não salariais") caracterizados pela possibilidade de revisão ou interpretação das normas.

No que se refere à greve, tema que ganha maior importância no cenário previsto de expansão da livre negociação, o amplo direito ao seu uso é reconhecido, embora se mantenha a necessidade de lei específica para o disciplinamento no caso dos servidores públicos. Todas as ações que envolvem o exercício de greve - como as sobre ocupação de imóveis ou interdição de piquetes, por exemplo - passaram da competência da Justiça comum para a Justiça do Trabalho, o que pode ser considerado um avanço dado o caráter especializado desta última. Estas ações são importantes porque, se acolhidas pela justiça - como o foram, pela justiça comum, na greve dos bancários de 2004 - impedem o acesso às instalações da empresa e dificultam as negociações. As varas de trabalho igualmente julgam a abusividade da 
Quadro 1. Principais mudanças legislativas efetivadas no governo Cardoso.

\begin{tabular}{|c|c|c|}
\hline Medida Provisória & $1053 / 95^{10}$ & $\begin{array}{l}\text { Salários - Salários e as demais condições referentes ao trabalho } \\
\text { devem ser fixados e revistos por meio de negociação coletiva. }\end{array}$ \\
\hline Portaria & $865 / 95^{11}$ & $\begin{array}{l}\text { Em caso de incompatibilidade entre a legislação e as cláusulas sobre } \\
\text { condições de trabalho pactuadas em convenção ou acordo coletivo, o } \\
\text { fiscal do trabalho deve comunicar o fato à sua chefia imediata, que o } \\
\text { submeterá à consideração da autoridade regional, cabendo a esta } \\
\text { encaminhar a denúncia à Procuradoria Regional do Trabalho. Revela }\end{array}$ \\
\hline
\end{tabular}
uma nova concepção de política de fiscalização, que passaria de punitiva para de orientação.

\begin{tabular}{|c|c|c|}
\hline Decreto & $2100 / 96^{12}$ & $\begin{array}{l}\text { Denúncia da Convenção } 158 \text { da OIT - Esta convenção estabelece } \\
\text { normas que limitam a dispensa imotivada, de maneira que tanto a } \\
\text { despedida individual quanto a coletiva devem obedecer certos } \\
\text { procedimentos para que sejam consideradas juridicamente regulares. } \\
\text { Tramita no STF ADin contra o decreto. }\end{array}$ \\
\hline Lei & $9307 / 96^{13}$ & $\begin{array}{l}\text { Arbitragem - forma extrajudicial de resolução de conflitos pela qual } \\
\text { as partes obrigam-se à decisão de um terceiro. Debate-se, na Justiça } \\
\text { do Trabalho, se pode ser utilizada em contratos individuais. }\end{array}$ \\
\hline $\begin{array}{c}\text { Lei } \\
\text { Decreto }\end{array}$ & $\begin{array}{l}9601 / 98^{14} \\
2.490 / 98^{15}\end{array}$ & $\begin{array}{l}\text { Contrato por prazo determinado - Estabelecem e regulamentam o } \\
\text { contrato por prazo determinado, inclusive definindo medidas de } \\
\text { estímulo a essa contratação mediante a redução de encargos. Esse } \\
\text { contrato pode ser aplicado em qualquer atividade desenvolvida pela } \\
\text { empresa ou estabelecimento, por meio de convenção ou acordo } \\
\text { coletivo. A contratação é permitida por até } 02 \text { anos. MP com } \\
\text { incentivos não reeditada pelo governo sucessor. }\end{array}$ \\
\hline Medida Provisória & $1.709 / 98^{16}$ & $\begin{array}{l}\text { Banco de horas - A Lei } 9.601 / 98 \text { estabeleceu o banco de horas, que } \\
\text { possibilita que a jornada ultrapasse as atuais } 44 \text { horas semanais sem } \\
\text { que o trabalhador receba o pagamento de horas extras, desde que haja } \\
\text { compensação dessas horas ao longo de um período de quatro meses. } \\
\text { Essa MP amplia o prazo de compensação da jornada para um ano. }\end{array}$ \\
\hline $\begin{array}{c}\text { Emenda } \\
\text { Constitucional }\end{array}$ & $24 / 99^{17}$ & $\begin{array}{l}\text { Extingue os vogais da Justiça do Trabalho. Com essa emenda, as } \\
\text { Juntas de Conciliação e Julgamento foram transformadas em Varas } \\
\text { do Trabalho. }\end{array}$ \\
\hline Portaria & $1.964 / 99^{18}$ & $\begin{array}{l}\text { Consórcio de empregadores - O consórcio é uma união de } \\
\text { produtores rurais com a finalidade de contratar empregados rurais, } \\
\text { sendo outorgado a um dos produtores poderes para contratar e gerir } \\
\text { a mão-de-obra. }\end{array}$ \\
\hline Lei & $9.957 / 00^{19}$ & $\begin{array}{l}\text { Institui o procedimento sumaríssimo, ao qual está submetido todo } \\
\text { dissídio individual cujo valor não exceda a } 40 \text { vezes o salário mínimo } \\
\text { na data de ajuizamento da reclamação, excluídas as demandas em } \\
\text { que é parte a administração pública direta, as autarquias e as } \\
\text { fundações. }\end{array}$ \\
\hline Lei & $9.958 / 00^{20}$ & $\begin{array}{l}\text { Instaura as comissões de conciliação prévia, com representantes de } \\
\text { empregados e de empregadores, para tentar conciliar os conflitos } \\
\text { individuais do trabalho. Essas comissões podem ser instituídas por } \\
\text { grupos de empresa ou ter caráter intersindical. Interpretação liberal } \\
\text { da lei entende que toda demanda trabalhista deve ser submetida às } \\
\text { comissões, o que, uma vez obtido o acordo, este não seria passível de } \\
\text { ser apreciado pela Justiça do Trabalho. O STF posicionou-se contra a } \\
\text { impossibilidade de apreciação pela Justiça do Trabalho desses acordos. }\end{array}$ \\
\hline
\end{tabular}




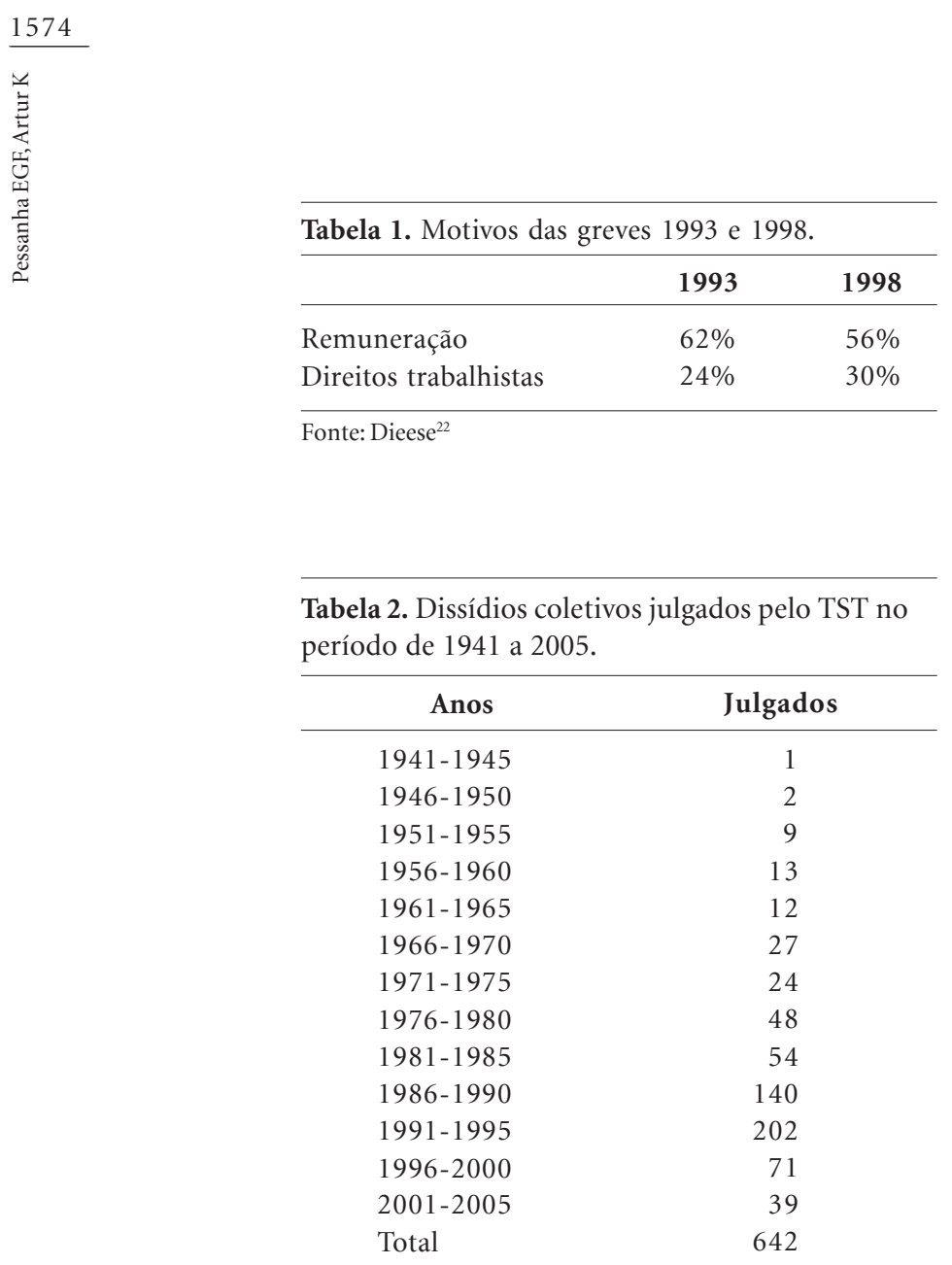

Fonte: TST

greve, ações cautelares para garantir serviços mínimos e contratação de substitutos em caso de atividades essenciais, assim como ações para impedir práticas antissindicais - como as de substituição ilegal de grevistas ou uso de força para obrigar o retorno de empregados ao trabalho. O movimento sindical manifesta sua preocupação principalmente com a definição dos limites de legalidade para contratar substitutos de grevistas, embora a proteção contra práticas antissindicais pareça ter saído fortalecida com a reforma.

Por outro lado, a Emenda 45 prevê que em caso de greve em atividade essencial com possibilidade de lesão do interesse público, o Estado pode, através do Ministério Público, ajuizar dissídio coletivo, competindo à Justiça do Trabalho, já aqui através de seus tribunais, julgar o mérito da greve, sua abusividade, etc. Considerada por muitos como um golpe no direito de greve, essa restrição é objeto de polêmica, pois se configura como a única possibilidade de interferência estatal frente à "garantia constitucional do direito de greve" e "só se justifica quando esse direito, exercido abusivamente, agride gravemente os interesses da comunidade".

Já o poder normativo da Justiça do Trabalho parece ter sido bastante atingido pela Reforma do Judiciário. Em complemento à perspectiva explicitamente negocial da proposta de Reforma Sindical, a Emenda 45 retirou da Justiça do Trabalho o poder - acolhido por todas as Constituições desde 1946 - de "criar ou estabelecer normas não existentes no ordenamento positivo ou nos acordos coletivos e convenções coletivas antes vigentes (entre as partes litigantes)", podendo torná-la, como já avaliou o jurista e sociólogo Evaristo de Moraes Filho, "inoperante para jul-

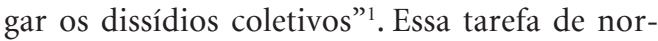
matização ficou predominantemente a cargo dos acordos ou convenções coletivas, e só o tempo poderá mostrar os efeitos dessas mudanças.

B) Por outro lado, com a tentativa de implementar mudanças negociadas de forma tripartite, o governo convocou o Fórum Nacional do Trabalho, que produziu o Projeto de Reforma Sindical. São pontos principais dessa Reforma, ainda não apreciada pelo Congresso Nacional:

. a criação de Conselho Nacional do Trabalho, com a participação das Centrais Sindicais; . as mudanças na organização sindical: pluralidade sindical (mas com um sindicato com representação exclusiva com base no índice mais alto de representatividade demonstrado segundo critérios definidos); contribuição associativa; representação no local de trabalho; negociação coletiva voluntária, em vários níveis, mas sempre via sindicatos; arbitragem privada ou pública (sempre esta quando natureza do conflito é jurídica); direito de greve garantido; definição de serviços essenciais conforme a OIT.

A Reforma tem também pontos que tem se revelado polêmicos: a manutenção da verticalização do sistema, com Centrais no topo; o poder exponenciado das Centrais; a ambiguidade das alterações em relação à unicidade e ao imposto sindical. Quanto à representação dos trabalhadores nos locais de trabalho, sabe-se que foi ponto de dissenso entre os representantes dos trabalhadores e dos empresários no Fórum, já que estes últimos não concordaram que essa representação passasse pelo controle dos sindicatos.

\section{O quadro atual}

O cenário do modelo de relações de trabalho no Brasil é de sua resistência às mudanças. Além da reforma sindical não ter saído do papel, o mercado de trabalho brasileiro continua altamen- 
te flexível. A rotatividade da mão de obra é alta (acima de 40\%) e a demissão facilitada (em 60\% dos casos, em 2007, sem justa causa, segundo dados do Dieese ${ }^{23}$ ). A Convenção 158 da OIT, contra demissão injustificada, que poderia ter revertido esse último aspecto, foi denunciada pelo governo Fernando Henrique, em 1996. O governo Lula a encaminhou para o Congresso Nacional em 2008, mas houve reações contrárias em Comissões de mérito. No plano dos direitos individuais, continuamos convivendo com o que Cardoso chamou de "flexibilização a frio dos direitos trabalhistas" 24 : as empresas enfrentam a lei e os tribunais com questões recorrentes a cada semana. Nesse ambiente, a terceirização é o maior fantasma, e objeto de confrontos entre patrões e sindicatos, os quais também envolvem a Justiça, principal lócus normativo do tema. A audiência pública do TST sobre terceirização, ocorrida em 2011, é um bom retrato do embate entre posições.

Três projetos principais sobre a terceirização movimentam o Congresso Nacional:

. o PL 4302/1998 encaminhado pelo ex-presidente Fernando Henrique Cardoso (PSDB-SP), com a proposta de flexibilizar a lei que permite o trabalho temporário e de regulamentar a intermediação de mão de obra por meio de empresas prestadoras de serviço.

. o PL 4330/2004, do deputado Sandro Mabel (PL-GO), que além de manter a mesma linha do projeto de $\mathrm{FHC}$, propõe a regulamentação das relações contratuais que envolvem a terceirização de forma direta, ou seja, isentando os empregadores de qualquer responsabilidade com os direitos dos trabalhadores.

. O Projeto de Lei elaborado pelo grupo de trabalho da CUT, discutido com as demais centrais sindicais e apresentado pelo deputado $\mathrm{Vi}$ centinho (PT/SP), leva a proposta que garante ao trabalhador terceirizado o direito à informação prévia, a proibição da terceirização na atividade-fim, a responsabilidade solidária da empresa contratante e a ampliação dos direitos dos trabalhadores do setor privado, ou seja, o fim da distinção de salários, das jornadas, dos benefícios e das condições de saúde e segurança entre os trabalhadores.

No plano das ações coletivas, as dificuldades introduzidas pela Reforma do Judiciário para a consecução de dissídios preocupam. Mas o sindicalismo tem sabido explorar brechas. Se dissídios de natureza econômica (salários, condições de trabalho) precisam de concordância dos patrões para serem instaurados (e alguns juízes não respeitam a exigência, que julgam, com razão, inconstitucional), os dissídios de natureza jurídica (para discutir desrespeito às normas, à lei) têm sido acionados.

O exemplo mais notório de tal uso ocorreu nos casos de demissões massivas, diante dos esperados efeitos da crise de 2008-2009, quando recorrendo a direitos constitucionais de garantia de trabalho e a convenções internacionais, sindicatos tiveram alguns ganhos no nível regional da Justiça do Trabalho. No TST, a Corte deu primazia aos parâmetros legais, tipificados em lei, em oposição aos princípios, priorizando ainda as razões de mercado para as demissões, conforme analisam Pessanha et al. ${ }^{7}$. Ressaltamos, no entanto, que a Seção de Dissídios Coletivos estabeleceu, para casos futuros, a premissa de que "a negociação coletiva é imprescindível para a dispensa em massa de trabalhadores", o que reforça o papel dos sindicatos nesses casos .

Há que se considerar, também, que a judicialização das relações de trabalho tem alcançado o Supremo Tribunal Federal, de modo que decisões judiciais e leis favoráveis aos trabalhadores têm sido questionadas nesse âmbito. Recentemente, como exemplo, a Confederação Nacional da Indústria apresentou uma Ação Direta de Inconstitucionalidade contra a lei que criou a Certidão Negativa de Débito Trabalhista, que torna obrigatória sua apresentação pelas empresas interessadas em participar de procedimentos licitatórios.

Existem alguns dados positivos, que merecem ser avaliados mais de perto.

. a consideração judicial dos danos morais, que podem ser objeto de reclamações trabalhistas;

. a aceitação judicial do instrumento da substituição processual (sindicatos representando conjuntos de trabalhadores, coletivizando pleitos individuais) vem se legitimando;

. o engajamento do TST no Programa Nacional de Prevenção de Acidentes, incluindo a recomendação para que os desembargadores dos Tribunais Regionais do Trabalho e juízes do trabalho encaminhem à Procuradoria da Fazenda Nacional cópia de condenações (sentenças e acórdãos) que reconheçam a conduta culposa do empregador em acidente do trabalho. Com essas informações, a Procuradoria poderá ajuizar ações regressivas com o objetivo do ressarcimento dos gastos decorrentes das prestações sociais (saúde e previdência) relativas aos acidentes.

. as mudanças nas súmulas do TST, tais como a ampliação do número de dirigentes sindicais com direito à estabilidade, e a necessidade de pe- 
rícia, no caso de atividades insalubres, para o estabelecimento de acordos coletivos em compensação de jornada, dentre outras apontadas como positivas pelo Dieese ${ }^{25}$.

. a recorrência ao Ministério Público pelos sindicatos, embora a ação civil pública diretamente impulsionada por estes (direito conferido pela Constituição de 1988) seja pouco frequente.

. a adoção, em 2010, da Convenção 151 da OIT, que contém diretrizes para a organização sindical dos servidores públicos e sua atuação no processo de negociação coletiva. No momento, debate-se a regulação da Convenção.

Repercussão institucional da precarização no setor de saúde: breves notas

Nesta parte do artigo, chamamos atenção para as principais questões que colocam em jogo o direito do trabalho, especialmente considerando os trabalhadores na área da saúde.

Segundo Dedecca ${ }^{26}$, o setor de saúde ocupa um papel importante na sustentação do mercado de trabalho no Brasil. Porém a recorrente formalização dos contratos de trabalho não está associada a trabalhos de qualidade, de modo que a precariedade manifesta-se pela baixa qualidade de contratos legais e pela flexibilidade por meio da existência de diversos tipos de vínculos empregatícios por trabalhador ocupado.

A precarização e a flexibilidade dos contratos de trabalho na área de saúde remetem-nos para dois temas principais que repercutem na Justiça do Trabalho e no Ministério Público do Trabalho. Tal análise torna-se importante a partir da abordagem sociológica da economia e do direito, que entende que os mercados não são autorregulados, devendo-se investigar as bases institucionais que conformam os contratos e suas consequências para a estabilidade ou precariedade dos $\operatorname{mesmos}^{27,28}$ ). Os temas aqui destacados são o da terceirização e o da jornada de trabalho.

Os argumentos econômicos, que demandavam a ampliação da licitude da terceirização no Brasil levaram o TST a permitir a terceirização em atividades-meio, por meio do Enunciado 331, de 1993, o qual também determinou a responsabilidade subsidiária da empresa principal em relação aos direitos trabalhistas dos trabalhadores, conforme mostra a pesquisa de Artur ${ }^{29}$.

O Enunciado 331, atualmente chamado de Súmula, foi aprovado em 1993. Em 2000, foi alterado para conferir a responsabilidade subsidiária também à Administração Pública. Em 2011, diante do julgamento pelo Supremo Tribunal
Federal, da Ação Direta de Constitucionalidade n. 16, incisos da Súmula 331 foram alterados no sentido de determinar que tal responsabilidade não resulta de mero descumprimento das obrigações trabalhistas pela empresa contratada, mas principalmente da conduta culposa da Administração Pública em não fiscalizar o cumprimento das obrigações contratuais e legais da prestadora do serviços.

Tal ação foi promovida pelo então governador do DF, com apoio de outros governadores visando à declaração da constitucionalidade do artigo 71, parágrafo primeiro, da Lei de Licitações $8666 / 93^{30}$, o qual retira do Estado a responsabilidade por encargos trabalhistas, fiscais e comerciais quando houver inadimplência. Tal estratégia buscou, na verdade, atacar indiretamente a Súmula 331 do TST, que, em seu inciso IV, determina a responsabilidade subsidiária da Administração Pública nas terceirizações.

Pesquisa na base virtual de jurisprudência do TST $^{31}$ mostra que os ministros têm sustentado que a declaração de constitucionalidade do artigo 71 da Lei de Licitações afastou a responsabilidade objetiva do Estado, mas não a responsabilidade subsidiária do ente público, com o objetivo de evitar a inadimplência dos direitos trabalhistas e previdenciários do empregado.

O tema é polêmico e, segundo mensagem recente da página do TST, a Seção de Dissídios Individuais/SDI-1 suspendeu o julgamento de processos sobre responsabilidade subsidiária de ente público diante do reconhecimento da repercussão geral do tema pelo STF, de modo que a decisão do STF servirá de paradigma para as demais decisões sobre a matéria.

Encontramos, apenas no período que vai da modificação da Súmula 331, em 2011, até março de 2012, 736 acórdãos que continham as palavras-chave terceirização, ente público e saúde, em processos que envolviam trabalhadores da saúde requerendo obrigações trabalhistas descumpridas e entes públicos contestando sua responsabilidade subsidiária nas terceirizações.

Por sua vez, o Ministério Público do Trabalho tem adotado uma postura institucional de sensibilidade para as práticas irregulares na Administração Pública, com orientações que podem ser aplicadas no setor de saúde pública. Por meio de orientação da Coordenadoria Nacional de Combate às Irregularidades na Administração Pública (CONAP), "o Ministério Público do Trabalho é parte legítima para investigar e processar na Justiça do Trabalho questões que envolvam a terceirização irregular na administração pública, 
independentemente da existência de regime jurídico para o provimento dos cargos efetivos objetos da terceirização." (Orientação 1- Ata da Reunião Nacional de 09.03.2004).

Especificamente, a CONAP possui orientações que visam a estabelecer critérios para a atuação do Ministério Público do Trabalho de modo a coibir terceirizações fraudulentas, os contratos que desrespeitem os critérios legais que permitem sua temporariedade, bem como os contratos sem concurso público, conforme o Quadro 2.

De toda forma, o debate sobre ampliação das possibilidades lícitas de terceirização continua vivo. Diante da necessidade de legitimação de uma nova decisão uniforme sobre o tema, pela primeira vez na história, o TST convocou, inclusive, uma audiência pública para discussão do tema, que ocorreu em outubro de 2011. Nela, sindicatos e especialistas alertaram o tribunal sobre a realidade de precarização dos direitos do trabalho trazida pela terceirização.

Em relação à ampla temática da jornada de trabalho, segundo Silva ${ }^{33}$, o TST, a partir da década de 1990, operou dentro de um contexto em que conferiu ampla validade à flexibilização por meio da negociação coletiva. Isso afeta, sem dúvida, uma área como a da saúde, onde os trabalhadores são atingidos diretamente por jornadas de trabalho longas, rodízios de horários, excesso de horas-extras, etc. Nesse ambiente, o TST $^{34}$ tem estabelecido que a jornada 12 x 36 (horas) por meio de negociação coletiva, é válida. $\mathrm{O}$ Tribunal, porém, não tem aceitado que, na jornada 12 x 36, haja a concessão parcial ou a supressão, por convenção ou acordo coletivo, do intervalo intrajornada, por se tratar de matéria de ordem pública, sendo devidas, nessa hipótese, as horas extras.

Quadro 2. Exemplos de Orientações do Ministério Público do Trabalho sobre Administração Pública Irregular

\begin{tabular}{|c|c|c|}
\hline Terceirização & $\begin{array}{l}\text { Orientação 11. Substituição de servidor público por } \\
\text { terceirizado. Impossibilidade. Não é possível a substituição } \\
\text { de servidor público por terceirizado, em atividade inserida } \\
\text { na estrutura de provimento efetivo do tomador, por } \\
\text { importar em mera intermediação de mão de obra. (Ata } \\
\text { da Reunião Nacional de 09.03.2004) }\end{array}$ & $\begin{array}{l}\text { Proibição substituição } \\
\text { do servidor público } \\
\text { pelo terceirizado }\end{array}$ \\
\hline $\begin{array}{c}\text { Contratação } \\
\text { temporária }\end{array}$ & $\begin{array}{l}\text { Orientação 33. São critérios objetivos para aferição da } \\
\text { regularidade da contratação por prazo determinado, nos } \\
\text { termos do art. 37, IX, da CF: a) Previsão em lei; b) } \\
\text { Processo Seletivo (em regra); c) Cumprimento das hipóteses } \\
\text { justificadoras de excepcional interesse público previstas na } \\
\text { lei; d) Temporariedade; e) Ato administrativo motivando a } \\
\text { contratação. }\end{array}$ & $\begin{array}{l}\text { Inconstitucionalidade } \\
\text { de leis e de } \\
\text { contratações que } \\
\text { desrespeitem os } \\
\text { critérios para a } \\
\text { legalidade da } \\
\text { temporariedade }\end{array}$ \\
\hline $\begin{array}{c}\text { Comissionamento } \\
\text { Irregular }\end{array}$ & $\begin{array}{l}\text { Orientação n. 25. Contratação de médicos e dentistas em } \\
\text { municípios de difícil acesso. Concurso público } \\
\text { inviabilizado por formação de cartéis. O concurso público } \\
\text { deve ser exigido para a contratação de médicos e dentistas } \\
\text { em municípios de difícil acesso. Na hipótese de se } \\
\text { constatar, no caso concreto, a formação de cartéis de } \\
\text { médicos e dentistas, a fim de inviabilizar o } \\
\text { preenchimento das vagas por concurso público, o } \\
\text { Procurador do Trabalho oficiante deverá promover } \\
\text { discussões com outros ramos do Ministério Público e da } \\
\text { sociedade civil do Município diretamente afetado, de } \\
\text { modo a conscientizar a população local e as autoridades } \\
\text { públicas municipais acerca dos riscos que tais medidas } \\
\text { representam para a saúde da população. (Ata da Reunião } \\
\text { Nacional de 18.04.2005 }\end{array}$ & $\begin{array}{l}\text { Valorização do } \\
\text { concurso público }\end{array}$ \\
\hline
\end{tabular}

Fonte: Elaborado pelas autoras a partir de D'Ambroso ${ }^{32}$, procurador do trabalho da 12a Região (SC), coordenador regional da Coordenadoria Nacional de Combate às Irregularidades na Administração Pública, diretor legislativo do Instituto de Estudos e Pesquisas Avançadas da Magistratura e do Ministério Público do Trabalho. 
Deve-se observar que, diferentemente do argumento de que tal sistema de jornada permite o descanso do trabalhador, a realidade de múltiplos vínculos de emprego dos trabalhadores da saúde tem significado a realização da jornada de 12 x 36 em múltiplos estabelecimentos, o que tem sensibilizado o Ministério Público do Trabalho. Em Araraquara (SP), por exemplo, o Ministério Público do Trabalho ${ }^{35}$ firmou termo de ajustamento de conduta (TAC) com dez hospitais da região a fim de adequar a jornada de trabalho dos profissionais de saúde, pois, atualmente, muitos contratados no sistema de 12 horas de trabalho por 36 horas de descanso atuam em mais de um estabelecimento.

O Dieese ${ }^{36}$ também registrou um elevado número de trabalhadores da saúde que trabalham além do limite legal das 44 horas semanais, sendo que os vínculos adicionais são outra modalidade de extensão do tempo trabalhado que se tornou usual na área da saúde. Paralelamente, vários estudos têm demonstrado os efeitos perniciosos dessas práticas sobre os profissionais de várias formações que atuam na área da saúde.

Concluímos este tópico com a constatação de que os temas da terceirização e da jornada de trabalho na área da saúde têm mobilizado as instituições e os atores sociais. Militantes de diferentes centrais e confederações, em atividades da $14^{\text {a }}$ Conferência Nacional de Saúde, manifestaramse pelo combate à terceirização na saúde e pela redução da jornada de trabalho para diferentes trabalhadores do setor, conforme notícia veiculada pela $\mathrm{CUT}^{37}$. Ainda, segundo o DIAP ${ }^{38}$, a Mesa Diretora da Câmara dos Deputados acatou a proposta de emenda à Constituição (PEC) que altera o artigo 197 da Constituição Federal, destinada a proibir a terceirização e a privatização da mão de obra das ações e serviços de saúde.

\section{Considerações finais}

O quadro traçado anteriormente mostra que é urgente recolocar na agenda pública as reformas sindical e trabalhista no Brasil a fim de retomarse o processo de concertação social para o redesenho do modelo de relações de trabalho.

O sentido da reforma trabalhista aqui defendido envolve principalmente a necessidade de enfrentar-se a existência de um mercado de trabalho extremamente heterogêneo, com trabalhadores com acesso a diferentes conjuntos de direitos, especialmente considerando os empregados diretos e os terceirizados. Por outro lado, é fundamental pensar em formas institucionais de representação coletiva dos trabalhadores excluídos da formalidade trabalhista. O movimento sindical pode ainda explorar as possibilidades abertas com a ampliação da competência da Justiça do Trabalho pela Reforma do Judiciário para tratar de "relações de trabalho" e não apenas de "relações de emprego".

Não menos importante é a questão das diversas formas de discriminação enfrentadas por certos grupos da população no mercado de trabalho. Segundo a OIT ${ }^{39}$, apesar da redução, ainda perduram expressivas desigualdades de gênero e raça no mercado de trabalho brasileiro. Outros aspectos que merecem atenção, segundo a Organização, são os níveis elevados de desemprego juvenil bem como a continuidade das políticas de redução do trabalho infantil.

Ainda, seguindo a perspectiva de $\operatorname{Sen}^{40}$, a expansão das capacidades humanas são a chave e o objetivo do desenvolvimento. Nessa direção, a melhoria das políticas de formação profissional e inovação é vital para atingirmos objetivos como crescimento econômico e a construção de instituições democráticas.

Por fim, para o setor de saúde, há que se considerar a necessidade da representação desses trabalhadores e de suas demandas por condições contratuais dignas e isonômicas, afinal, torna-se inviável uma política de saúde que desconsidere a importância da qualidade das relações de trabalho no setor. 


\section{Colaboradores}

EGF Pessanha e K Artur participaram igualmente de todas as etapas de elaboração do artigo.

\section{Referências}

1. Brasil. Presidência da República. Casa Civil. Subchefia para Assuntos Jurídicos. Decreto 19.770, de 19 de março de 1931. Regula a sindicalisação das classes patronaes e operarias e dá outras providências. [documento da Internet]. [acessado 2013 abr 25]. Disponível em: http://www.planalto.gov.br/ccivil_03/ decreto/Antigos/D19770.htm

2. Moraes Filho E. O Problema do Sindicato Único no Brasil - seus Fundamentos Sociológicos. São Paulo: Alfa-Ômega; 1998.

3. Arbix G. Uma aposta no futuro - os primeiros anos da Câmara Setorial da Indústria Automobilística. São Paulo: Scritta; 1996.

4. Morel RLM, Pessanha E, Gonzaga S, Mangabeira W. Perspectivas do sindicalismo no Rio de Janeiro hoje: debate sobre o contrato coletivo de trabalho. In: Villas Boas G, Gonçalves MA, organizadores. $O$ Brasil na Virada do Século. Rio de Janeiro: RelumeDumará; 1995. p. 53-75.

5. Cardoso AM, Comin Á. Câmaras Setoriais, modernização produtiva e democratização nas relações de trabalho no Brasil: a experiência do setor automobilístico. In: Castro NA, organizadora. A Máquina e o Equilibrista - Inovações na Indústria automobilística brasileira. Rio de Janeiro: Paz e Terra; 1995. p. 387-427.

6. Diniz E. Crise, Reforma do Estado e Governabilidade. Rio de Janeiro: FGV; 1997.

7. Pessanha E, Alemão I, Soares JL. TST, dissídios coletivos, demissão massiva: novos desafios para a Justiça do Trabalho. In: Coutinho GF, Melo Filho HC, Souto Maior JL, Fava MN, organizadores. $O$ Mundo do Trabalho, Volume I: leituras críticas da jurisprudência do TST: em defesa do direito do trabalho. São Paulo: LTr; 2009. p. 77-94.

8. Krein JD. O aprofundamento da flexibilização das relações de trabalho no Brasil nos anos 90 [dissertação]. Campinas (SP): Unicamp; 2001.

9. Artur K. O TST frente à terceirização. São Carlos: EDUFSCar, Fapesp; 2007.

10. Brasil. Medida provisória 1053, de 30 de junho de 1995. Dispõe sobre medidas complementares ao Plano Real e dá outras providências. Diário Oficial da União 1995; 1 jul.

11. Brasil. Ministério do Trabalho e Emprego. Portaria 865, de 14 de setembro de 1995. Estabelece critérios de fiscalização de condições de trabalho constantes de Convenções ou Acordos Coletivos de Trabalho. Diário Oficial da União 1995; 15 set.

12. Brasil. Decreto $\mathrm{n}^{\circ} 2.100$, de 20 de dezembro de 1996. Torna pública a denúncia, pelo Brasil, da Convenção da OIT no 158 relativa ao Término da Relação de Trabalho por Iniciativa do Empregador. Diário Oficial da União 1996; 23 dez.

13. Brasil. Lei 9.307, de 23 de setembro de 1996. Dispõe sobre a arbitragem. Diário Oficial da União 1996; 24 set.

14. Brasil. Lei 9.601, de 21 de janeiro de 1998. Dispõe sobre o contrato de trabalho por prazo determinado e dá outras providências. Diário Oficial da União 1998; 22 jan. 
15. Brasil. Decreto 2.490, de 4 de fevereiro de 1998. Regulamenta a Lei no 9.601, de 21 de janeiro de 1998, que dispõe sobre o contrato de trabalho por prazo determinado e dá outras providências. Diário Oficial da União 1998; 5 fev.

16. Brasil. Medida provisória 1.709 , de 6 de agosto de 1998. Dispõe sobre o trabalho a tempo parcial, faculta a extensão do benefício do Programa de Alimentação do Trabalhador - PAT ao trabalhador dispensado e altera dispositivo da Consolidação das Leis do Trabalho - CLT. Diário Oficial da União 1998; 7 ago.

17. Brasil. Emenda constitucional No 24, de 9 de dezembro de 1999. Altera dispositivos da Constituição Federal pertinentes à representação classistas na Justiça do Trabalho. Diário Oficial da União 1999; 10 dez.

18. Brasil. Ministério do Trabalho e Emprego. Portaria 1.964, de 1 de dezembro de 1999. Diário Oficial da União 1999; 2 dez.

19. Brasil. Lei 9.957, de 12 de janeiro de 2000. Acrescenta dispositivos à Consolidação das Leis do Trabalho, aprovada pelo Decreto-Lei no 5.452, de 10 de maio de 1943, instituindo o procedimento sumaríssimo no processo trabalhista. Diário Oficial da União 2000; 13 jan.

20. Brasil. Lei 9.958, de 12 de janeiro de 2000. Altera e acrescenta artigos à Consolidação das Leis do Trabalho - CLT, aprovada pelo Decreto-Lei no 5.452 de 10 de maio de 1943, dispondo sobre as Comissões de Conciliação Prévia e permitindo a execução de título executivo extrajudicial na Justiça do Trabalho. Diário Oficial da União 2000; 13 jan.

21. Noronha EG, De Negri F, Artur K. Custos do trabalho, direitos sociais e competitividade industrial. In: Negri JD, Negri FD, Coelho D, editores. Tecnologia, exportação e emprego. Brasília: IPEA; 2006. p. 161-201.

22. Departamento Intersindical de Estatística e Estudos Socioeconômicos (DIEESE). Negociações Coletivas no Brasil; 2001.

23. Departamento Intersindical de Estatística e Estudos Socioeconômicos (DIEESE). A Convenção 158 da OIT e a garantia contra a dispensa imotivada [Nota Técnica, n.61]. Rio de Janeiro: DIEESE; 2008.

24. Cardoso AM. A Década Neoliberal e a Crise dos Sindicatos no Brasil. São Paulo: Boitempo; 2003.

25. Departamento Intersindical de Estatística e Estudos Socioeconômicos (DIEESE). TST aprova mudanças em sua jurisprudência. [Nota Técnica, n. 103]. Rio de Janeiro: DIEESE; 2011.

26. Dedecca CS. O trabalho no setor de saúde. São Paulo em Perspectiva 2008; 22(2):87-103.

27. Edelman LB. Rivers of law and contested terrain: a Law and Society approach to Economic Rationality. Law and Society Review 2004; 38(2):181-197.

28. Stryker R. Half, empty, full or neither? Law inequality and social change in capitalist democracies. Annual Review of Law and Social Science 2007; 3:69-97.
29. Artur K. O novo poder normatizador do TST: dissídios individuais e atores coletivos. São Paulo: LTr; 2012.

30. Brasil. Lei 8666, de 21 de junho de 1993. Regulamenta o art. 37, inciso XXI, da Constituição Federal, institui normas para licitações e contratos da Administração Pública e dá outras providências. Diário Oficial da União 1993; 22 jun.

31. Tribunal Superior do Trabalho (TST). Jurisprudência. [documento da Internet]. [acessado 2012 mar 10]. Disponível em: www.tst.gov.br

32. D’Ambroso MJF. Terceirização na Saúde Pública. [documento da Internet]. [acessado 2012 fev 28]. Disponível em: http://www.ipeatra.org.br/site/artigos/ 2010/10/terceirizacao_na_saude_publica; 2010

33. Silva SGCLD. Relações Coletivas de Trabalho: configurações institucionais no Brasil Contemporâneo. São Paulo: LTr; 2008.

34. Tribunal Superior do Trabalho (TST). SDI -1 rejeita adicional de horas extras em jornada $12 \times 36$. No tícias do TST 2008; 17out. [documento da Internet]. [acessado 2012 mar 10]. Disponível em: www.tst. gov.br

35. Tribunal Superior do Trabalho (TST) JusBrasil 2009; (279). [página na Internet]. [acessado 2012 fev 13]. Disponível em: http://mpt.jusbrasil.com.br/noticias/ 677877/profissionais-de-saude-que-trabalhem-emmais-de-um-local-nao-poderao-cumprir-jornada$12 \times 36$

36. Departamento Intersindical de Estatística e Estudos Socioeconômicos (DIEESE). Boletim Trabalho na Saúde-1998-2008; 2009.

37. Central Única dos Trabalhadores (CUT). Mobilização marca o primeiro dia da $14^{\circ}$ Conferência Nacional de Saúde. São Paulo: CUT; 2011. [documento da Internet]. [acessado $2012 \mathrm{fev} \mathrm{13].} \mathrm{Disponível} \mathrm{em:}$ http://www.cut.org.br/destaques/21555/militanciacutista-ocupa-a-esplanada-dos-ministerios-no-atoem-defesa-do-sus

38. Departamento Intersindical de Assessoria Parlamentar (DIAP). 16/02/2012. Deputado apresenta PEC que proíbe terceirização na saúde $(16 / 06 / 12)$ [documento da Internet]. [acessado 2012 mar 10]. Disponível em: http://www.diap.org.br/index.php/noticias/agencia-diap/19702-deputado-apresentapec-que-proibe-terceirizacao-na-saude-

39. Organização Internacional do Trabalho (OIT). Perfil do trabalho decente no Brasil. Brasília, Genebra: OIT; 2009.

40. Sen A. Development as Freedom. New York: Knopf; 1999.

Artigo apresentado em 11/08/2012

Aprovado em 27/09/2012

Versão final apresentada em 02/10/201 